\title{
FIGURAS DE LO MISMO Y DE LO OTRO: ENTRE LO SEMIÓTICO Y LO POLÍTICO
}

\author{
FIGURES OF THE SAME AND THE OTHER: \\ BETWEEN THE SEMIOTIC AND THE POLITICAL
}

\author{
Maria Augusta BABO \\ Universidade Nova de Lisboa \\ mab@fcsh.unl.pt
}

\begin{abstract}
Resumen: En esta presentación, pretendemos exponer las aporías que nos permiten definir el Mismo en relación con el Otro. El Otro es un término que ya incluye una oposición a Mismo. El Otro es relacional. Se trata de analizar, en las diversas posiciones lógicas que los términos Otro e Mismo pueden tomar en el cuadrado semiótico, las figuras correspondientes al Mismo y al Otro y concebir que hay un ajedrez político que se dibuja en estas confrontaciones que establece el cuadrado semiótico. Establecer el límite o los límites entre el Mismo y el Otro nos permite pensar sobre el marco geopolítico actual.
\end{abstract}

Palabras clave: Mismo. Otro. Vecino. Extranjero.

Abstract: In this presentation, we intend to expose the insoluble contradiction that allow us to define the Self in relation to the Other. The Other is a term that already includes an opposition to the Self. The Other is relational. We intend to analyze, in the various logical positions that the terms Other and Self can take in the semiotic square, the figures corresponding to the Same and the Other and to conceive that there is a political chess that is drawn in these confrontations that the semiotic square establishes. Establishing the border or the boundaries between the Self and the Other this allows us to think about the current geopolitical framework.

Key Words: Self. Other. Neighbour. Foreign. 


\section{LAS APORÍAS DEL OTRO}

El Otro es un término muy particular, ya que, al establecer una oposición al Mismo, incluye, en esa oposición, la relación en sí. Se trata de una disyunción inclusiva. En el Otro está contenida la categoría de alteridad y la relación que esta categoría tiene con la primera categoría: el Mismo. Aparente y lógicamente, el Mismo anticipa al Otro, es el término original. Pero, desde un punto de vista conceptual, diría que el Otro es el fundador del Mismo. Es que no hay identidad sin alteridad.

Primeramente, debemos concebir un Otro de lo Mismo. El Otro de lo Mismo afirma la cesura del sujeto, que ya está en el término griego Diabole, que significa división. Y Diabolos, lo que se extravía, es una figura cristiana amenazadora que ya señala la segmentación interna de la que hemos hablado. Si el Otro como Maligno está en las profundidades del Mismo, significa que la identidad del mismo, en su interior más íntimo, es sacudida de inmediato. Freud se dio cuenta de esta división del sujeto a través del tópico del inconsciente. Deconstrucción de la unicidad del sujeto como categoría del pensamiento occidental.

La modernidad del pensamiento freudiano se basa en el hecho de que el sujeto ya no es una categoría esencialista, una, completa, e por lo tanto incorpora la otredad. Esta división problematiza el estado de las identidades, mostrando que la unicidad de la identidad es de un orden ficticio, es decir, producido por el imago. Lacan viene a nombrar estos otros de "pequeños otros" con los cuales el sujeto se mimetiza en el proceso de constitución imaginaria. En un tiempo como el nuestro de proliferación de imágenes, el sentimiento de identidad nunca ha sido tan fuerte. Todas las instancias, individuales, colectivas, tribales, hoy reclaman sus identidades. La identidad se ha convertido así en un reclamo político y social.

¿Qué es el sujeto? Pregunta a la que el pensamiento del siglo XX trató de responder. La semiótica puede ayudarnos definiendo el sujeto en sus programas narrativos $\mathrm{y}$, sobre todo, en sus trayectos narrativos, trazando la distancia del primero al segundo.

En este juego de oposición entre lo Mismo y el Otro, se manifiestan varias aporías. Veamos.

Si el Otro es siempre otro de lo mismo, es decir, relacional, sin 
embargo, en su irreductibilidad, el Otro es del orden de lo Mismo, dejando de ser, por lo tanto, Otro. Esta aporía llevaría a definir lo Mismo contra lo Otro. Cuanto más el otro es Otro, más asegura la identidad de lo Mismo. La xenofobia es, por lo tanto, un refuerzo de la identidad internalizada frente a la amenaza del otro exterior. Puede ser el bárbaro como figura de lo no asimilable, del enteramente Otro. El monstruo, el bárbaro, el inhumano siempre son considerados como Otros, una alteridad intocable sin contaminación al propio cuerpo: y, por lo tanto, del orden de lo Mismo. Sabemos que la historicidad de lo humano siempre se ha fortalecido a través de la identificación de Otros colocados fuera del límite humano, lo que constituye para Agamben (2002: 30), la desconexión fundacional de la idea misma de lo humano y la dimensión política de la separación.

Sus límites crean un refuerzo de identificación, ya que la alteridad se muestra como un absoluto innegable, porque inhumano. El monstruo es la figura del otro absoluto, más allá de ese límite, desde el cual el humano es impensable e i-mencionable. Paradójicamente, el monstruo se convierte en lo que le permite a la humanidad pensarse. Lo Mismo se crea frente al insoportable Otro. Delimitando un límite exterior que lo alberga de la monstruosidad. El Otro se convierte, al mismo tiempo, en la otredad y la exterioridad. El filósofo portugués José Gil afirma esta idea cuando dice: "El hombre produce monstruos por una sola razón: para poder pensarse en su propia humanidad" (1994: 56).

Pero esta oposición fuerte entre lo Mismo y el Otro permite, mediante una operación de negación de los términos, la creación de otras dos figuras opuestas entre sí. A la operación que niega tanto el Mismo como el Otro le llamaría alteración. Otrar — neologismo portugués introducido por Bernardo Soares, el semi-heterónimo de Fernando Pessoa, en el Libro de la inquietud: "Me gusta otrarme" - es cambiar. Todo este universo heterológico se abre en el devenir otro, en el imperceptible devenir (el devenir-animal de Deleuze) que atraviesa el imaginario de nuestro archivo literario, desde Pessoa hasta Kafka. Cambiar es pasar, transponer. La alteración afecta tanto a la mismidad como a la otredad. El pensamiento de la otredad, tanto en la reflexión sobre el Otro como en la reflexión sobre las prácticas de alteración, constituye el programa narrativo completo de la contemporaneidad. 


\section{PARA UNA SEMIÓTICA DEL OTRO}

En esta doble negación, del Otro y de lo Mismo, nos encontramos con las figuras a que llamaría el Vecino (lo Familiar) y el Extranjero (el Extraño). Lo Vecino es un término que resulta de la negación del Otro, y que presupone lo Mismo, mientras que el Extranjero resulta de la negación de lo Mismo y presupone el Otro:

\section{Mismo}

Otro

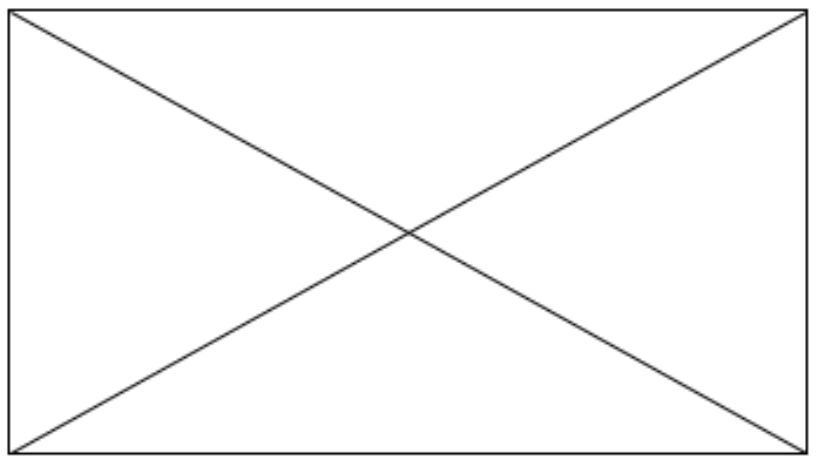

Vecino

Extranjero

El cuadrado semiótico permite formular la red estructural de términos en sus relaciones recíprocas y también las aporías que resultan de ellas. A este respecto, tenemos de volver a pensar en Freud y en su concepto de Unheimlich: una extrañeza familiar, una inquietud familiar como una alteración de lo íntimo. Freud explica (1933: 200) que la inquietante extrañeza es la "intimidad de la casa" una vez reprimida y que vuelve como un extraño. Es en este contexto que introduce y explica el tema del doble. Ahora, esta extraña inquietud es el resultado de una oposición no disyuntiva entre lo familiar y lo extraño, por ejemplo, del orden de la subjetividad.

\section{LA DIMENSIÓN POLÍTICA DE LA ALTERIDAD}

Pero hay también una dimensión política del Extraño y de lo Familiar. Pensar la alteridad en su dimensión política pasa por analizar las 
figuras del extranjero - el término francés abarca ambos los registros-y el similar, el hermano, el vecino. Todo un programa político se extiende desde las xenofobias emergentes en nuestra sociedad, hasta la práctica de la hospitalidad, pero también un cuestionamiento sociológico. Del extraño al invitado, hay separación, una línea fronteriza. $\mathrm{O}$, como lo trata Landowski (1997: 17), un juego entre asimilación y exclusión en un fundo de indistinción. Es que el hostil es, al mismo tiempo, el extranjero y el apátrida, el huésped y el enemigo; eso nos pone todavía la cuestión de los límites y conexiones entre lo político y lo jurídico, en la medida en que cabe a la ley regular fenómenos como las migraciones, los refugiados, la ciudadanía, entre muchos otros con los que nos deparamos hoy.

De hecho, el término inicial para hospes es hostil, según Benveniste (1969). El radical hostil no tiene ninguna connotación de hostilidad, refiriéndose a lo extranjero. Y más: "Un hostis no es un extranjero en general". A diferencia de los peregrinos que viven fuera de las fronteras del territorio, hostis es "el extranjero, mientras que se reconocen derechos iguales a los de los ciudadanos romanos". Este reconocimiento de derechos implica una cierta relación de reciprocidad, suponiendo una convención: no se llama hostis a cualquiera que no es romano. Se establece "un vínculo de igualdad y reciprocidad entre este extranjero y el ciudadano romano que puede conducir a la noción precisa de hospitalidad" (Benveniste, 1969: 93). De este modo, el lingüista presenta el hostis equiparado a la ciudadanía romana. Pero hostis perdió fuerza en el mundo romano: "Cuando la vieja sociedad se convirtió en una nación, se abolieron las relaciones de hombre a hombre, de clan en clan; solo quedaba la distinción de lo que está dentro o fuera de la civitas. Debido a una mutación de la que no conocemos las condiciones precisas, la palabra hostis adquirió el significado de 'hostil' y desde entonces solo se aplica al "enemigo"” (1969: 95).

Como resultado, la noción de hospitalidad se expresó con un término diferente donde el antiguo hostis todavía existe, según Benveniste (1969). Y, por lo tanto, en la etimología de los términos, todavía recuperamos el Otro indiferenciado que nos lleva a asociar hospes y hostis, es decir, establecer una relación común entre hospitalidad y hostilidad. Esta cuestión se convierte entonces en un tema ético-político básico, dependiendo de la posición a la que relegamos al Otro en su relación con el Mismo. De esta pregunta — ¿qué lugar ocupa el Otro en el umbral del interior? - se encarga Derrida en la obra De l'hospitalité (Dufourmentell, 
1997). Cuestión que simplemente plantea los nuevos requisitos éticos para el problema de la inmigración y de la migración en general. Para el filósofo, la cuestión ético-política de la hospitalidad incondicional es la negación o más bien la superación de la dicotomía que es una antinomia, como lo que señala Derrida entre la Ley y las leyes, que se impone en el eje de los subcontrarios: extranjero/ hostil vs. vecino/invitado. Bueno, cómo separar o por qué separar, en una ético-política de la hospitalidad absoluta, aquellos que Derrida nombra: "Los 'desplazados', los exiliados, los deportados, los expulsados, los desarraigados, los nómadas". Y podríamos extender: las personas sin hogar, los apátridas, los inmigrantes, los refugiados, los clandestinos... Al mismo tiempo, toda la migración contemporánea. En todos los casos de figura, lo que prevalece es un topos: el interior y el borde, por el cual el Otro siempre está afuera. Todas estas figuras y aquellos que las encarnan, es decir, cuya carne se ha vuelto anónima, sin rostro, sin nombre, padecen la misma condición: estar allí donde no es posible existir.

Terminamos citando a Landowski, cuando dice que:

Es en este contexto que, de ahora en adelante, se desarrolla, alli y allá, un discurso social de búsqueda o reconquista de una identidad concebida como “amenazada” y que surgen las prácticas de confrontación sociocultural, a veces de carácter dramático, que se pensaba que estaban desaparecidas, como si se tratara de traer a lo diferente, una vez más, el extranjero en primer lugar, el "métèque", pero aun así el "marginal”, el "excluido", el "desviado”, etc. a una posición de exterioridad (Landowski, 1997: 16).

\section{REFERENCIAS BIBLIOGRÁFICAS}

AGAMBEN, G. (2002). L'Ouvert - de l'homme et de l'animal. Paris: Bibliothèque Rivage.

BENVENISTE, E. (1969). Le vocabulaire des institutions indoeuropéennes - 1. Economie, parenté, société. Paris: Les Éditions de Minuit.

DUFOURMENTELL, A. (1997). Jacques Derrida à répondre - De l'hospitalité. Paris: Calmann-Lévy.

FREUD, S. (1933). Essais de psychanalyse appliquée. Paris: Idées / Gallimard.

GIL, J. (1994). Monstros. Lisboa: Quetzal. 
LANDOWSKI, E. (1997). Présences de l'autre. Paris: PUF.

Recibido el 2 de marzo de 2020.

Aceptado el 15 de abril de 2020. 